\title{
Is there still a role for mediastinoscopy as the first mediastinal staging procedure in lung cancer?
}

\author{
${ }^{1} \mathrm{D}$ Waller, ${ }^{2} \mathrm{KM}$ Skwarski \\ ${ }^{1}$ Consultant Thoracic Surgeon, Glenfield Hospital, Leicester, UK; ${ }^{2}$ Consultant Respiratory Physician, Royal Infirmary of Edinburgh, UK
}

\begin{abstract}
Lung cancer staging has evolved with the advent of endobronchial and endoscopic ultrasound (EBUS and EUS) as an alternative to mediastinoscopy and other surgical staging techniques. This has led to the debate now as to what the first-line staging investigation should be. Mr Waller makes the case that although EBUS and EUS are welcomed staging techniques, mediastinoscopy still has an important role as the first-line staging investigation in specific scenarios (when there is potentially surgically resectable mediastinal disease). Dr Skwarski argues that EBUS and EUS should be used in conjunction with CT-PET and considered as a complete alternative to mediastinoscopy.
\end{abstract}

KEYWORDS Lung cancer, staging, mediastinum, mediastinoscopy, endobronchial ultrasound, endoscopic ultrasound

\author{
Correspondence to D Waller \\ Glenfield Hospital \\ Leicester LE3 9QP \\ tel +44 (0) II 2583959 \\ e-mail David.waller@uhl-tr.nhs.uk
}

Correspondence to KM Skwarski, Royal Infirmary of Edinburgh Little France Crescent Edinburgh, EHI6 4SU UK

tel +44 (0) I 3 I 242 I898 e-mail kristopher.skwarski@luht. scot.nhs.uk

DECLARATION OF INTERESTS No conflicts of interest declared.

\section{There is still a role for mediastinoscopy as the first mediastinal staging procedure in lung cancer}

D Waller

ABSTRACT In the face of increasing evidence of the efficacy of endoluminal ultrasonic biopsy methods (endobronchial ultrasound-guided transbronchial needle aspiration [EBUS-TBNA] and endoscopic ultrasound-guided fine needle aspiration [EUS-FNA]) it would seem perverse to argue that a more invasive surgical operation such as mediastinoscopy should be preferred as a first-line investigation. However, more careful study of the indication for staging and developments in the technique of mediastinoscopy will identify specific scenarios where this may be appropriate and will challenge the idiom that EBUS-TBNA and EBUS-FNA is always first choice.

\section{INTRODUCTION}

Reference to contemporary lung cancer management guidelines' would suggest that in the majority of cases endobronchial ultrasound-guided transbronchial needle aspiration (EBUS-TBNA) and endoscopic ultrasoundguided fine needle aspiration (EUS-FNA) is an appropriate first procedure in the staging of the mediastinum. However, there is emerging evidence that a change in the threshold for resection will have an impact on the staging pathway for selected patients.

\section{THERE IS EVIDENCE FOR RESECTION IN SINGLE ZONE N2A NON-SMALL CELL LUNG CARCINOMA}

In a recent edition of the tumour, node and metastasis (TNM) classification for lung cancer, ${ }^{2}$ exploratory analyses indicated that lymph node stations could be grouped together into six 'zones': peripheral or hilar for NI, and upper or lower mediastinal, aortopulmonary, and subcarinal for N2 nodes (Figure I). Among patients undergoing resection without induction therapy, there were three distinct prognostic groups: single-zone $\mathrm{NI}$, multiple-zone $\mathrm{NI}$ or single-zone N2 and multiple-zone N2 disease. A similar five-year survival rate from single-zone $\mathrm{N} 2 \mathrm{a}$ and multi-zone $\mathrm{NIb}$ of $35 \%$ has been found. It is therefore logical to suggest that as surgical resection is recommended for stage II disease it should also be considered (in the context of adjuvant chemotherapy) for stage IIIA N2a disease. Many surgeons are now adopting this policy. ${ }^{3}$ However, it must be noted that the favourable survival rates for $\mathrm{N} 2 \mathrm{a}$ disease are derived from post-operative pathological staging achieved with intraoperative systematic nodal dissection. 


\section{PREOPERATIVE STAGING MUST BE COMPARABLE WITH INTRAOPERATIVE LYMPH NODE DISSECTION}

To justify operating primarily on this evidence one must duplicate the standard of operative staging prior to the procedure. In other words the mediastinal nodes must be removed in order to be certain that only one zone is malignant. The EBUS-TBNA and EBUS-FNA does not have a sufficiently high negative predictive value (NPV) to fulfil these requirements. In the radiologically normal mediastinum (with no enlarged nodes), EBUS-TBNA and EBUS-FNA is highly effective with a sensitivity of up to $68 \%$ and a NPV of $91 \% .{ }^{4}$ Yasufuku et al. found no significant differences between EBUS-TBNA and EBUS-FNA and mediastinoscopy in determining the true pathologic $N$ stage in a population in which the prevalence of N2/N3 disease was $35 \% .^{5}$ So a negative EBUS-TBNA and EBUS-FNA means that a surgical diagnostic exploration of the mediastinum may be omitted. However, in potential surgical patients with suspected N2 disease on a positron emission tomography-computed tomography (PET-CT) scan, the conclusions are somewhat different. Cerfolio et al. found in these patients that EBUS-TBNA and EBUS-FNA had a NPV of $79 \%$ and sensitivity of only $57 \%$; EBUS alone had a NPV of $80 \%$ and sensitivity of $63 \%$ but mediastinoscopy faired significantly better with $88 \%$ sensitivity, $93 \%$ NPV and $95 \%$ accuracy. ${ }^{6}$ Despite these findings many have used the alternative results of the Assessment of Surgical sTaging vs Endoscopic ultrasound in lung cancer: a Randomised clinical (ASTER) trial to promote EBUS-TBNA and EBUS-FNA as the first staging

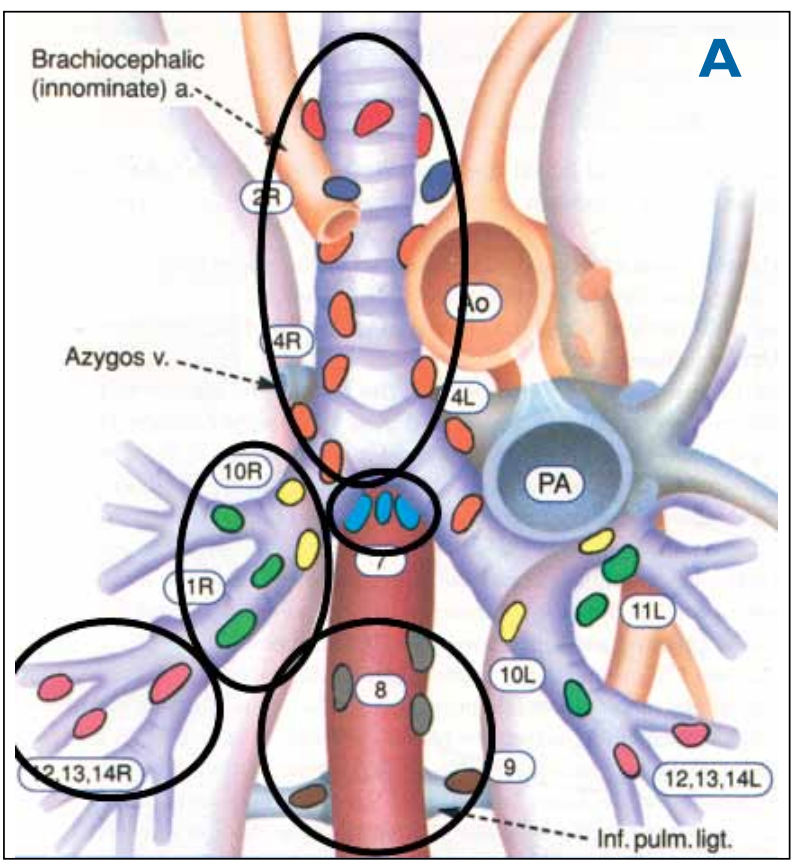

procedure. $^{7}$ In the group staged by mediastinoscopy the false negative rate was unusually high and $18 \%$ of subsequent operations were for N2 disease. This suggests that the conduct of the mediastinoscopic staging may have been suboptimal.

\section{THE TECHNIQUE OF MEDIASTINOSCOPY MUST BE OPTIMISED}

Some of the comparative deficiencies in mediastinoscopy may be a result of the operator rather than the approach. If surgical staging is to be compared with EBUS-TBNA and EBUS-FNA then the following modifications are required. Video assistance using specifically designed scopes improves visualisation and its negative predictive value to over $98 \%{ }^{8}$ It also allows for bimanual dissection which facilitates more than just lymph node biopsy. Video-assisted mediastinoscopic lymphadenectomy (VAMLA) is the closest approximation available of intraoperative systematic lymph node dissection. It is guided by anatomical landmarks, very similar to an open lymphadenectomy. It includes en bloc resection of the right and central compartments and dissection and lymphadenectomy of the left-sided compartments. Particular attention must be paid to the subcarinal space where the oesophagus should be displayed to ensure complete lymph node dissection of station seven. Indeed this is the commonest site of false negative biopsies in conventional mediastinoscopy. ${ }^{8}$ Criticisms that VAMLA is a very specialised technique which occupies excessive theatre time do not seem justified. Witte et al. reported a mean duration of 54

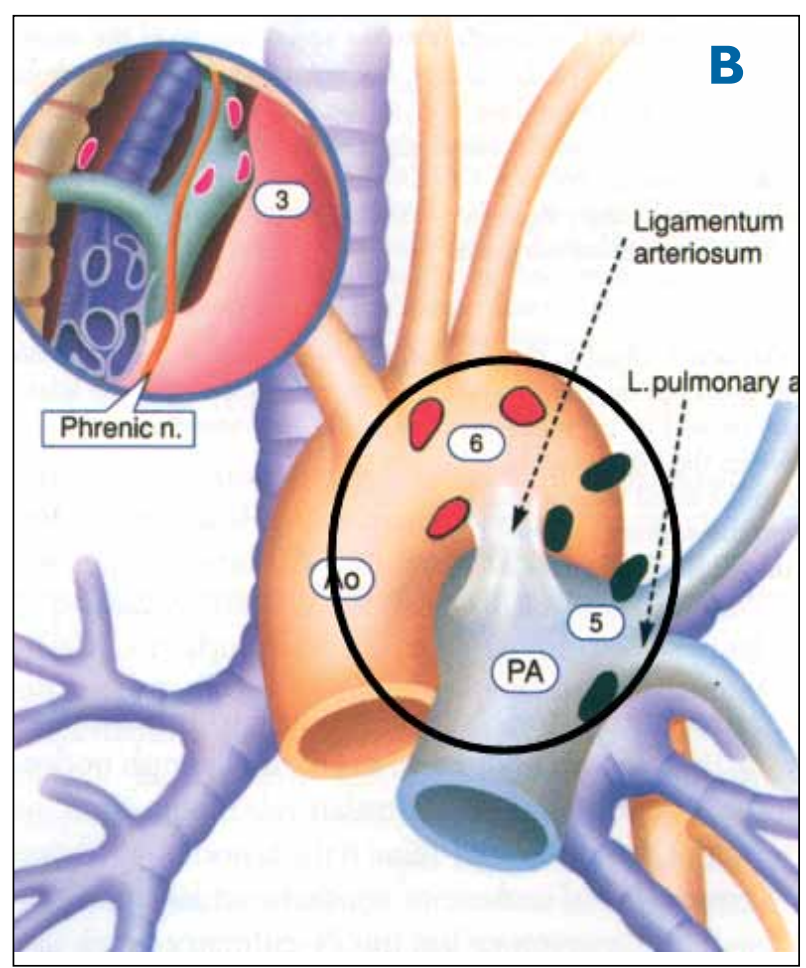

FIGURES IA AND IB The six lymph node zones. 


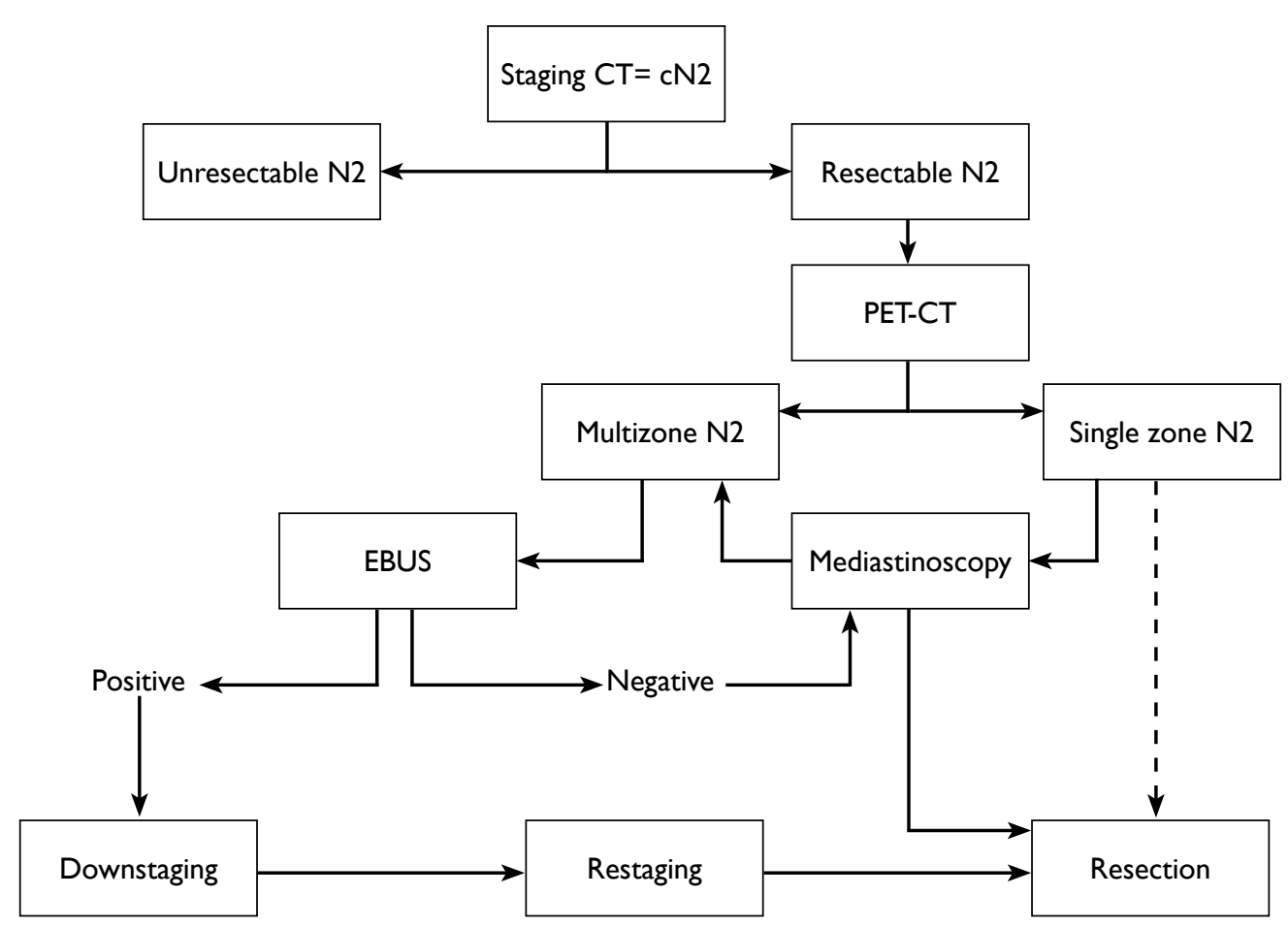

EBUS= endobronchial ultrasound-guided

PET-CT= positron emission tomography-computed tomography

$\mathbf{C T}=$ computed tomography

FIGURE 2 A suggested staging algorithm for clinical N2 disease.

minutes and a complication rate of $4.6 \%$ with a sensitivity of $93.8 \%$, a specificity of $100 \%$, and a falsenegative rate of $0.9 \%$. $^{9}$ However, there does appear to be a learning curve to overcome. ${ }^{10}$ To really maximise surgical staging, the addition of video-assisted thoracoscopic mediastinal lymph node dissection gives complete access to aortopulmonary and inferior mediastinal lymph node zones" and matches the range of lymph node zones accessible by EBUS-TBNA and EBUS-FNA but in addition gives direct visualisation and the access to remove rather than just needle puncture the lymph nodes.

\section{GO STRAIGHT TO MEDIASTINOSCOPY TO AVOID DELAY}

If surgery is contemplated primarily in patients with resectable clinical $\mathrm{N} 2 \mathrm{a}$ disease (as suggested by a PETCT scan), then all other accessible nodal zones should be proven to be benign pathologically. A negative EBUSTBNA and EBUS-FNA will require confirmatory mediastinoscopy and these patients must be sufficiently fit for anaesthetic (since resection is contemplated) so why not use the definitive method initially? This will enable staging and resection to be completed within the 3I-day target time. Figure 2 illustrates a suggested algorithm for mediastinal staging. The initial decision (in conjunction with the surgeon) is whether the extent of N2 disease is resectable. If not, due to the bulkiness or local relations of the nodes, then EBUS-TBNA and EBUS-FNA is the staging procedure of choice. Similarly if there is evidence on the PET-CT scan of multi-zone N2 disease then EBUS-TBNA and EBUS-FNA should be used next. Negative results should then be confirmed by mediastinoscopy.

\section{CONCLUSION}

As a thoracic surgeon I welcome the advent of endoscopic ultrasonic mediastinal staging. Its use by experienced operators frees up theatre time for definitive therapeutic surgery. Its advent has also forced surgeons to improve their mediastinoscopy technique. However, as always, physicians should not get carried away by overenthusiasm for a 'new toy'. Pragmatism dictates that in selected patients where the purpose is to identify a true negative, one should use the most reliable technique in the first instance. In cases of lung cancer, albeit the minority, video-assisted mediastinoscopy (with lymphadenectomy) should be the first mediastinal staging procedure. 


\section{REFERENCES}

I Lim E, Baldwin D, Beckles $M$ et al. Guidelines on the radica management of patients with lung cancer. Thorax 2010; 65 Suppl 3 I-27. http://dx.doi.org/I0.II36/thx.20I0.145938

2 Rusch VW, Crowley J, Giroux DJ et al. The IASLC lung cancer staging project: proposals for the revision of the $\mathrm{N}$ descriptors in the forthcoming seventh edition of the TNM classification for lung cancer. J Thorac Oncol 2007; 2:603-12.

3 Tanner NT, Gomez M, Rainwater C et al. Physician preferences for management of patients with stage IIIA NSCLC: impact of bulk of nodal disease on therapy selection. J Thorac Oncol 20I 2; 7:365-9. http://dx.doi.org//0.1097/JTO.0b013e3/823a385t

4 Szlubowski A, Zieliński M, Soja J et al. A combined approach of endobronchial and endoscopic ultrasound-guided needle aspiration in the radiologically normal mediastinum in non-smallcell lung cancer staging - a prospective trial. Eur J Cardiothorac Surg 2010; 37:I I75-9. http://dx.doi.org/10.1016/j.ejcts.2009.II.015

5 Yasufuku K, Pierre A, Darling G et al. A prospective controlled trial of endobronchial ultrasound-guided transbronchial needle aspiration compared with mediastinoscopy for mediastinal lymph node staging of lung cancer. J Thorac Cardiovasc Surg 201I; 142:1393-400. http://dx.doi.org/ /0.10 I6/j.jtcvs.201 I.08.037

6 Cerfolio RJ, Bryant AS, Eloubeidi MA et al. The true false negative rates of esophageal and endobronchial ultrasound in the staging of mediastinal lymph nodes in patients with non-small cell lung cancer. Ann Thorac Surg 2010; 90:427-34. http://dx.doi. org/10.1016/j.athoracsur.2010.04.062
7 Annema JT, van Meerbeeck JP, Rintoul RC et al. Mediastinoscopy vs endosonography for mediastinal nodal staging of lung cancer: a randomized trial. JAMA 2010; 304:2245-52. http://dx.doi. org/l0.100I/jama.20I0.1705

8 Anraku M, Miyata R, Compeau C et al. Video-assisted mediastinoscopy compared with conventional mediastinoscopy: are we doing better? Ann Thorac Surg 2010; 89:1577-8I. http://dx.doi. org/10.1016/j.athoracsur.2010.02.012

9 Witte B, Hürtgen M. Video-assisted mediastinoscopic lymphadenectomy (VAMLA). J Thorac Oncol 2007; 2:367-9. http://dx.doi. org/10.1097/0I.JTO.0000263725.895I2.d7

I0 Sayar A, Citak N, Metin M et al. Comparison of video-assisted mediastinoscopy and video-assisted mediastinoscopic lymphadenectomy for lung cancer. Gen Thorac Cardiovasc Surg 20I I; 59:793-8. http://dx.doi.org/I0.1007/s I I748-0 I I-0819-8

II Witte B, Messerschmidt A, Hillebrand $\mathrm{H}$ et al. Combined videothoracoscopic and videomediastinoscopic approach improves radicality of minimally invasive mediastinal lymphadenectomy for early stage lung carcinoma. Eur J Cardiothorac Surg 2009; 35:343-7. http://dx.doi.org//0.1016/j.ejcts.2008.09.044

\section{CONFERENCING AND EVENTS}

The Royal College of Physicians of Edinburgh has a unique blend of rooms providing the perfect location for your conference, meeting or event. The Victorian Great Hall, galleried New Library and the Georgian Cullen Suite are wonderful settings for dinners and receptions. The modern Conference Centre seats up to 300 people in raked seating and is complemented by breakout rooms seating from 10 to 150 people, a keypad voting system and video conferencing. The College provides a stunning setting for weddings and receptions and is licensed for both civil and religious ceremonies. Discounts are available for Fellows and Members, medical conferences and charities.

For more information or for a quotation, please contact the Events Team on +44 (0) I3। 225 7324; email events@rcpe.ac.uk or visit http://www.rcpe-venue.co.uk

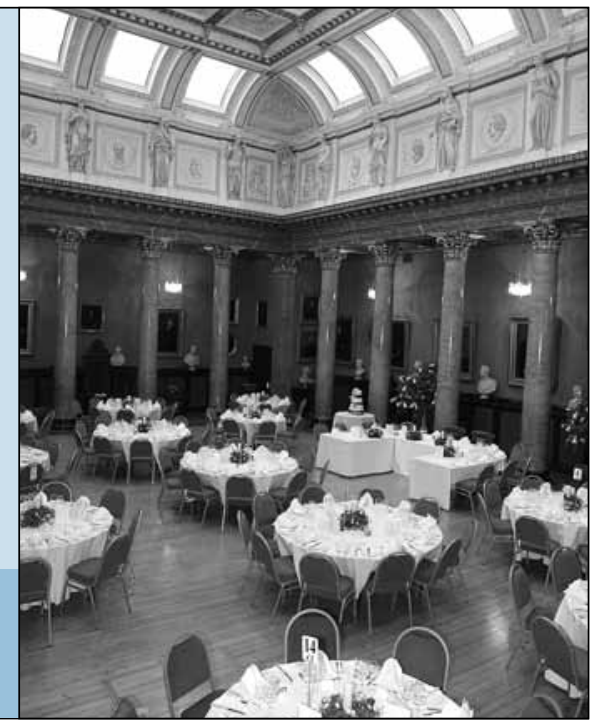




\title{
Endobronchial ultrasound-guided transbronchial needle aspiration (EBUS-TBNA) and endoscopic ultrasound-guided fine needle aspiration (EUS-FNA) should be the first-line mediastinal staging procedure in lung cancer
}

\author{
K Skwarski
}

ABSTRACT Accurate mediastinal staging determines available treatment options and prognosis in lung cancer. Evaluation of mediastinal lymph node involvement is crucial in lung cancer staging. Mediastinoscopy, with 70-95\% sensitivity, is the gold standard in the assessment of mediastinal lymph nodes. However, endoluminal ultrasound techniques in conjunction with a positron emission tomography-computerised tomography (PET-CT) scan are a safe, effective and less invasive alternative to mediastinoscopy. In the majority of cases, such procedures should be considered first-line in the staging algorithm for lung cancer.

\section{INTRODUCTION}

Precise staging is paramount in lung cancer.Tumour spread to local and regional lymph nodes (Figure I) determines suitability for surgical resection, which offers the best chance of cure. It is therefore imperative to identify nodal spread accurately prior to resection in order to prevent futile thoracotomy and tumour recurrence.

Currently, computerised tomography (CT) and a positron emission tomography with a CT scan (PET-CT) provide a non-invasive means of assessing mediastinal lymph node involvement in lung cancer. However, these techniques lack sensitivity and specificity. Typically, PETCT at best offers sensitivity and specificity of $79 \%$ and $93 \%$ respectively, with a false positive rate of $15 \%$.'

\section{THE GOLD STANDARD}

The gold standard in mediastinal staging of lung cancer has been mediastinoscopy. This highly invasive procedure has well-recognised complications, requires general anaesthesia, is costly and can usually only be performed once. Standard mediastinoscopy allows access to anterior and superior lymph node stations 2, 3, 4 and 7 (Figure I). However, access to the posterior and inferior mediastinum is limited. Despite this, sensitivity is typically 79-93\% with a false negative rate around $11 \%{ }^{2}$

\section{'MEDICAL MEDIASTINOSCOPY'}

Endobronchial ultrasound-guided transbronchial needle aspiration (EBUS-TBNA) is now emerging as an accurate minimally-invasive technique allowing access to the majority of mediastinal and hilar lymph node stations (stations 2, 3, 4, 7, 10, II). ${ }^{3}$ Together with endoscopic ultrasound-guided fine needle aspiration (EUS-FNA) through the oesophagus, which enables sampling of lymph node stations $4 \mathrm{~L}, 5,7,8$ and 9, ${ }^{3}$ a so-called 'medical mediastinoscopy', can now be performed (Figure I). In comparison to conventional surgical mediastinoscopy,

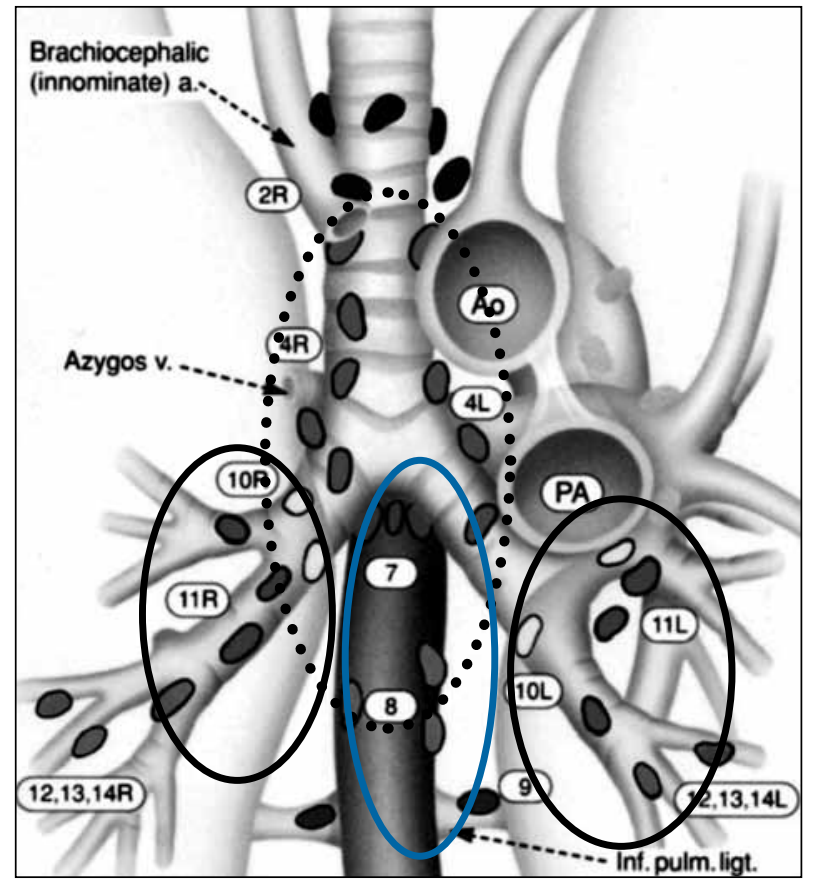

FIGURE I Hilar and mediastinal lymph node stations. Dotted circle signifies lymph node stations accessible by mediastinoscopy and EBUS-TBNA. Solid black circles signify lymph node stations accessible by EBUS-TBNA only. Blue circle signifies lymph node stations accessible by EUS-FNA.

such less invasive mediastinal staging procedures are carried out as a day case with patients under conscious sedation, with considerable cost savings. Furthermore, they are safe and well-tolerated by patients. As operator experience is steadily increasing, such techniques are becoming established in lung cancer staging algorithms.

Herth et al. ${ }^{4}$ reported high sensitivity and specificity of EBUS-TBNA even in the radiologically normal mediastinum. He concluded that patients with non-small cell lung carcinoma (NSCLC) with no significant mediastinal lymphadenopathy on CT (lymph nodes less than $\mathrm{I} \mathrm{cm}$ ) benefit from pre-surgical EBUS-TBNA as a first-line staging procedure. The sensitivity and specificity 
of EBUS-TBNA for detecting malignancy was $92.3 \%$ and $100 \%$ respectively, with a negative predictive value of 96.3\%. In this series no complications were observed. Jasufuku et al. ${ }^{5}$ reported a prospective study of 102 patients with potentially resectable NSCLC who underwent EBUS-TBNA. A total of 200 lymph nodes larger than $5 \mathrm{~mm}$ (measured during procedure) were sampled. Malignancy was detected in 24 patients with a diagnostic accuracy of $98 \%$ when comparing EBUSTBNA results with post-operative tissue analysis.

In the recently completed Assessment of Surgical sTaging vs Endoscopic ultrasound in lung cancer: a Randomised (ASTER) clinical study, ${ }^{6}$ EBUS-TBNA and EUS-FNA followed by mediastinoscopy if negative vs surgical staging in potentially resectable lung cancer, the sensitivity of the endosonographic arm was significantly higher (94\%) than the surgical staging arm (79\%). There were significantly fewer futile thoracotomies reported in the endosonographic group (7\%) compared to the surgical staging arm of (18\%). Further analysis showed that there was significantly better quality of life scores reported post-staging procedures in the endosonographic group vs the surgical group.?

In our institution, EBUS-TBNA has been performed routinely since 2004 . Our results show a sensitivity of $96 \%$ with a high negative predictive value (NPV) of $94 \%$. The false negative rate is $7 \%$ (internal audit).

\section{MEDIASTINOSCOPY - 'THE END OF THE ERA OF THE GOLD STANDARD?’}

Recently, Jasufuku et al. ${ }^{8}$ reported an excellent agreement of $91 \%$ between EBUS-TBNA and mediastinoscopy for mediastinal staging in patients with confirmed or suspected NSCLC. Patients with potentially resectable disease underwent EBUS-TBNA followed by mediastinoscopy if negative. If both staging procedures were negative for N2 or N3 disease, patients underwent pulmonary resection with mediastinal lymphadenectomy. The mean size of sampled lymph nodes by EBUS-TBNA was $6.9 \pm 2.9 \mathrm{~mm}$. The prevalence of N2 or N3 disease was $35 \%$. Specificity and positive predictive value for both techniques were $100 \%$. The sensitivity, NPV, and diagnostic accuracy of EBUS-TBNA were 81\%, 91\%, 93\% and for mediastinoscopy $79 \%, 90 \%$ and $93 \%$, respectively. No significant differences were found between EBUSTBNA and mediastinoscopy in predicting pathologic nodal status.

The role of surgical mediastinoscopy as the gold standard in cases where nodal spread is suspected on radiological grounds can now be challenged. EBUSTBNA \pm EUS-FNA and mediastinoscopy achieve similar results for the mediastinal staging of lung cancer.

EBUS-TBNA \pm EUS-FNA can replace mediastinoscopy in accurate staging of patients with potentially resectable NSCLC (Figure 2).

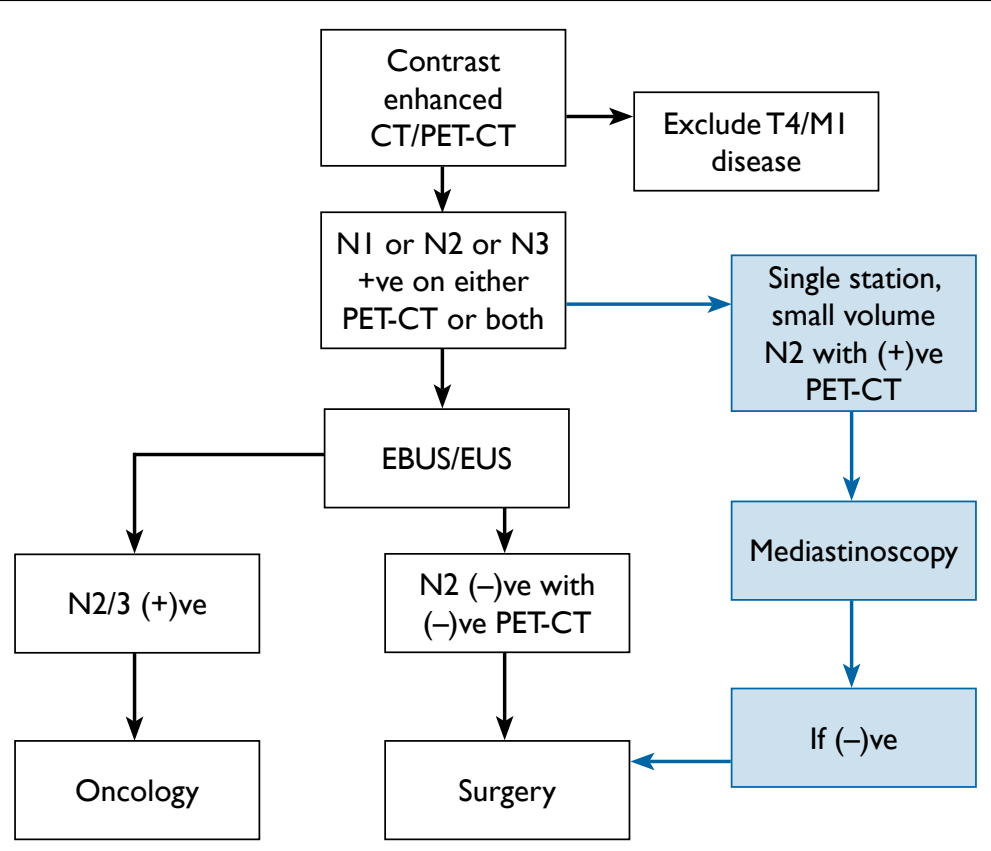

EBUS $=$ endobronchial ultrasound

EUS= endoscopic ultrasound

PET-CT= positron emission tomography-computerised tomography

$\mathbf{C T}=$ computerised tomography

FIGURE 2 Proposed staging algorithm for non-small cell lung cancer (in blue optional variant). 


\section{A WORD OF WISDOM}

Endosonographic techniques used in mediastinal and hilar staging of lung cancer have not been invented to replace mediastinoscopy. Both techniques should complement each other to benefit patients.

Many centres will proceed to mediastinoscopy as a firstline staging procedure in patients with single station, small volume mediastinal lymphadenopathy with positive CT-PET (Figure 2). Such an approach is driven by the fact that if EBUS-TBNA \pm EUS-FNA was to provide a negative result for malignancy in such cases, mediastinoscopy, 'the gold standard', would be performed prior to resection for confirmation due to lack of many centre's experience, and as a result confidence, in such new techniques.

\section{CONCLUSION}

As a respiratory physician and an interventional pulmonologist I welcome the development of new minimally invasive techniques in staging of lung cancer. During the last decade increasing use of EBUS-TBNA \pm EUS-FNA has improved accurate lymph node sampling significantly helping guide decision-making with regards to surgical resection and oncological management of lung cancer. The relative simplicity and excellent sensitivity of endosonographic sampling of hilar and mediastinal lymph nodes has prompted oncologists to increasingly utilise such techniques to optimise radiotherapy planning and subsequently the treatment of lung cancer. EBUSTBNA \pm EUS-FNA in conjunction with PET-CT has been proven as a safe, effective and precise method of mediastinal and hilar lymph node sampling and staging. Therefore, EBUS-TBNA \pm EUS-FNA can be considered as an alternative to mediastinoscopy in the modern staging of lung cancer.

\section{REFERENCES}

I De Wever W, Ceyssens S, Mortelmans L et al. Additional value of PET-CT in the staging of lung cancer: comparison with CT alone, PET alone and visual correlation of PET and CT. Eur Radiol 2007; 17:23-32. http://dx.doi.org//0.1007/s00330-006-0284-4

2 Detterbeck FC, Jantz MA, Wallace $M$ et al. Invasive mediastinal staging of lung cancer: ACCP evidence-based clinical practice guidelines (2nd edition). Chest 2007; 132 (3 Suppl): 202S-220S.

3 Rintoul RC, Skwarski KM, Murchison JT et al. Endobronchial and endoscopic ultrasound-guided real-time fine-needle aspiration for mediastinal staging. Eur Respir J 2005; 25:4 I6-2I. http://dx.doi.org/ 10.1183/09031936.05.00095404

4 Herth FJ, Ernst A, Eberhardt R et al. Endobronchial ultrasoundguided transbronchial needle aspiration of lymph nodes in the radiologically normal mediastinum. Eur Respir J 2006; 28:910-4. http://dx.doi.org/I0.II83/09031936.06.00I24905

5 Yasufuku K, Nakajima T, Motoori K et al. Comparison of endobronchial ultrasound, positron emission tomography, and CT for lymph node staging of lung cancer. Chest 2006; 130:710-8. http://dx.doi.org//0.1378/chest.130.3.710

6 Annema JT, van Meerbeeck JP, Rintoul RC et al. Mediastinoscopy vs endosonography for mediastinal nodal staging of lung cancer: a randomized trial. JAMA 2010; 304:2245-52. http://dx.doi. org/l0.100I/jama.2010.1705

7 Rintoul RC, Annema JT, Tournoy KG et al. Cost-effectiveness and quality of life results from the ASTER study: endobronchial and endoscopic ultrasound vs surgical staging in potentially resectable lung cancer. Thorax 201I; 66:A27. http://dx.doi.org//0.1/36/ thoraxjnl-20I I-201054b.55

8 Yasufuku K, Pierre A, Darling G et al. A prospective controlled trial of endobronchial ultrasound-guided transbronchial needle aspiration compared with mediastinoscopy for mediastinal lymph node staging of lung cancer. J Thorac Cardiovasc Surg 201I; I42:1 393-400. http://dx.doi.org/I0.10 I6/j.jtcvs.20I I.08.037 